\title{
EFEITO DA METFORMINA E DO ÁCIDO LIPÓICO NAS RESERVAS DE GLICOGÊNIO DE MÚSCULOS DENERVADOS E DE RATOS DIABÉTICOS
}

\author{
THE EFFECT OF METFORMIN AND LIPOIC ACID ON GLYCOGEN RESERVES \\ OF DENERVATED AND DIABETIC RAT MUSCLES
}

Carlos Alberto da Silva ${ }^{1}$ \& Rinaldo Guirro ${ }^{2}$

\begin{abstract}
1'Docente da Faculdade de Ciências Matemáticas e da Natureza - UNIMEP. ${ }^{2}$ Docente da Faculdade de Ciências da Saúde - UNIMEP Correspondência: Prof.Dr. Carlos Alberto da Silva. Faculdade de Ciências Matemáticas e da Natureza. Universidade Metodista de Piracicaba. Rodovia do Açúcar, Km156, Bairro Taquaral. Cep: 13400-901. Piracicaba - S.P. cvsilva@bestway.com.br
\end{abstract}

SILVA CA \& GUIRROSILVA CA \& GUIRRO R. Efeito da metformina e do ácido lipóico nas reservas de glicogênio de músculos denervados e de ratos diabéticos. Medicina, Ribeirão Preto, 33: 490-498, out./dez.2000.

RESUMO: As ações da insulina ocorrem após sua ligação ao receptor e conseqüente ativação de seus substratos citoplasmáticos. Tecidos de indivíduos resistentes à insulina, incluindo adipócitos, músculo e fígado mostraram diminuição na atividade do receptor, enquanto estudos realizados com tecidos de pacientes com diabetes mellitus, não dependentes de insulina, mostraram diminuição na ação da insulina, quando comparados com indivíduos normais. Muitos trabalhos sugerem que concentrações terapêuticas de metformina (MET) estimulam a atividade de substratos ligados aos receptores de insulina. Recentes estudos têm sugerido que o ácido tióctico (TA), substância antioxidante, usada no tratamento do diabetes, também exerce efeito periférico, melhorando o transporte e metabolismo da glicose. No presente estudo, foi avaliado o efeito metabólico do ácido tióctico $\left(0,1 \mathrm{mg} \cdot \mathrm{ml}^{-1}\right)$ e da metformina $\left(1.4 \mathrm{mg} \cdot \mathrm{ml}^{-1}\right)$ em estados de resistência à insulina, induzido pelo diabetes ou denervação muscular. Observou-se que a denervação e o diabetes promoveram a redução no conteúdo muscular de glicogênio (GLY), atingindo $60 \%$ no sóleo e $40 \%$ no gastrocnêmio. A MET induziu elevação nas reservas de GLY dos músculos normais, atingindo $297 \%$ no sóleo e $393 \%$ no gastrocnêmio. Foi observada, nos músculos de ratos diabéticos, redução no GLY, atingindo $50 \%$ no sóleo e $24 \%$ no gastrocnêmio. Por sua vez, MET e TA induziram elevação no conteúdo de GLY nos músculos de ratos diabéticos, atingindo $84 \%$ no sóleo e $44 \%$ no gastrocnêmio e $573 \%$ no sóleo e $296 \%$ no gastrocnêmio, respectivamente. No entanto, o tratamento com TA não apresentou efeito significativo sobre 0 conteúdo muscular de GLY de ratos normais ou denervados. Este estudo mostra que, nos músculos denervados, o tratamento com MET restabeleceu a capacidade de sintetizar glicogênio, apontando para a melhora no metabolismo das fibras. Por outro lado, nos músculos denervados, o tratamento com TA não promoveu efeito benéfico. Estes dados mostram que o estado de resistência à insulina, observado no diabetes, difere do estado de resistência observado nos músculos denervados.

UNITERMOS: Metformina. Ácido Tióctico. Glicogênio. Denervação Muscular. 


\section{INTRODUÇÃO}

A musculatura esquelética é, quantitativamente, um dos mais importantes tecidos envolvidos na homeostasia glicêmica, devido a sua capacidade de captar grandes quantidades de glicose após a infusão ou ingestão da mesma ${ }^{(1)}$. Diversos trabalhos têm relatado que a insulina ou a elevação na atividade contrátil das fibras ativam processos citosólicos, facilitadores da captação da hexose, a qual pode ser prontamente oxidada e liberada na forma de lactato, alanina ou piruvato, ou direcionada para a formação de glicogênio ${ }^{(2)}$.

A insulina se comunica com seus mensageiros de forma indireta através de proteínas citosólicas, ligadas ao substrato do receptor de insulina (IRS), as quais acoplam o receptor a várias moléculas efetoras, como, por exemplo, a fosfatidilinositol-3-quinase (PI3K), proteína ligadora do receptor para fator de crescimento (GRB2), a segunda homologia ao gene Src (SHP2) e molécula adaptadora da transcrição $(\mathrm{Nck})^{(3)}$. A PI3K é uma das principais proteínas envolvidas na mediação do sinal insulínico visto, que participa facilitando diferentes vias ligadas à ação da insulina, tais como: a captação de glicose, o efeito antilipólise, a síntese de glicogênio e a supressão da gliconeogênese $^{(4)}$. Na década de 90 , foi constatado que o IRS-1 fosforilado associa-se à enzima PI3K, ativando-a ${ }^{(5)}$. Demonstrou-se, ainda, que a associação e ativação da PI3K ocorre principalmente em dois importantes tecidos de ratos insulinodependentes, o fígado e o músculo ${ }^{(6)}$. Recentes estudos têm demonstrado que essa associação é essencial para o transporte de glicose no tecido muscular esquelético e car$\operatorname{díaco}^{(7,8)}$.

O transporte de glicose através das membranas das fibras musculares é mediado por uma família de transportadores denominados GLUT 1 e GLUT4 ${ }^{(9)}$. Com relação à função desses transportadores, sabese que o GLUT 1 é responsável pela captação basal de glicose, enquanto o GLUT 4, que é o mais importante, participa efetivamente do controle glicêmico, promovendo a captação de grandes quantidades de glicose, sendo passível de ser translocado de reservatórios vesiculares citosólicos em direção à membrana $^{(10,11)}$. No repouso, a proporção entre o GLUT 1 e o GLUT 4 é de 1:1, no entanto, na presença de insulina ou frente à elevação na atividade contrátil, a proporção passa a ser de $1: 5^{(12)}$.

Recentes estudos demonstraram que, concomitante à secção da inervação motora, ocorrem ex- pressivas modificações, relacionadas ao metabolismo de carboidratos, pelas fibras musculares esqueléticas, sendo merecedoras de destaque a resistência à insulina, desencadeada pela redução na concentração de PI3K, a diminuição da concentração citosólica do RNAm do GLUT4, alterações na atividade das enzimas participantes da glicólise, inativação da enzima de sintetase de glicogênio e a redução na habilidade da insulina em ativá-la. Estes eventos associados convergem para a redução na captação e no metabolismo da glicose predispondo as fibras musculares à atrofia ${ }^{(13)}$.

Alterações tanto na sensibilidade à insulina quanto no metabolismo da glicose também são observadas no diabetes mellitus, patologia onde já foram demonstradas redução na capacidade de a insulina se ligar ao seu receptor, redução na translocação do receptor de reservatórios citosólicos em direção à membrana, redução do RNAm ligado ao receptor, redução no processamento das vias pós-receptor, redução de $50 \%$ na atividade da IRS1 e na ativação da PI3K e redução na atividade da quinase de tirosina ligada ao receptor. Com a progressão da doença, observa-se desenvolvimento de resistência à insulina, redução na captação da glicose e na atividade das enzimas de hexoquinase, de desidrogenase de piruvato de desidrogenase de $\alpha$-cetoglutarato, as quais estão diretamente ligadas ao metabolismo da glicose ${ }^{(14)}$.

Dentre as substâncias prescritas no tratamento do diabetes tipo II, a metformina tem sido utilizada com sucesso no controle glicêmico dos pacientes com tal tipo de diabetes ${ }^{(15)}$. Sua ação anti-hiperglicemiante tem sido atribuída à combinação da redução na glicogenólise e na neoglicogênese hepática, associada à elevação na utilização de glicose por tecidos periféricos, principalmente no tecido muscular, sem elevar a secreção de insulina ou promover hipoglicemia, mesmo quando administrada experimentalmente, a indivíduos normoglicêmicos ${ }^{(16)}$.

Recentes estudos, realizados em ratos e humanos diabéticos, têm constatado que o tratamento com metformina é altamente efetivo em promover a melhora na sensibilidade muscular à insulina, auxiliando na redução do quadro de resistência insulínica ${ }^{(17)}$. Uma série de evidências sugerem uma interrelação entre a atividade da metformina e a enzima de hexoquinase, sugerindo que a metformina possa promover a melhora na atividade da enzima e facilitar os processos ligados à captação de glicose e à glicogênese ${ }^{(18)}$.

Dentre os novos tratamentos indicados para humanos diabéticos, resistentes à insulina, tem sido 
merecedora de destaque a administração parenteral de ácido lipóico ${ }^{(19,20)}$. Este ácido é transportado facilmente pelas membranas, sendo convertido em ácido diidrolipóico, o qual exerce uma infinidade de ações celulares, representadas, principalmente, por proteger as células da ação dos radicais livres, promover a redução na peroxidação lipídica, atuar como cofator de múltiplos complexos enzimáticos, elevar a expressão do GLUT 4 na musculatura, bem como facilitar na captação de glicose mediada pela insulina ${ }^{(21)}$.

Existem, pelo menos, duas condições diferenciadas, quando se observa o quadro de resistência à insulina, o diabetes e a denervação muscular. A proposta deste estudo foi avaliar in vivo as reservas de glicogênio do músculo sóleo e gastrocnêmio de ratos denervados ou de ratos diabéticos. Adicionalmente, verificamos se a metformina e o ácido lipóico, que conhecidamente diminuem o quadro de resistência muscular à insulina, no diabetes, podem, também, melhorar o quadro de resistência à insulina desencadeado pela denervação.

\section{MATERIAL E MÉTODOS}

\subsection{Animais}

Para a realização dos experimentos foram utilizados 72 ratos albinus, Wistar, obtidos do biotério da UNIMEP, Piracicaba, SP. Os ratos receberam água e alimentação ad libitum e foram mantidos em ambiente com temperatura constante ao redor de $23^{\circ} \mathrm{C} \pm 2^{\circ} \mathrm{C}$ e ciclo claro escuro de 12 horas.

\subsection{Grupos experimentais}

Os ratos foram adaptados às condições do biotério durante um período de duas semanas, sendo, posteriormente, divididos em grupos experimentais, conforme a Tabela I.

\subsection{Denervação}

Para denervação, os ratos foram anestesiados com pentobarbital sódico (40mg/Kg peso), tricotomizados na coxa direita onde, através de uma incisão de aproximadamente $0,5 \mathrm{~cm}$, o nervo ciático foi isolado e um pedaço de $5 \mathrm{~mm}$ do nervo foi retirado ${ }^{(22)}$. Após a cirurgia os ratos permaneceram em caixas individuais.

\subsection{Tratamento}

Os grupos de ratos tratados com metformina receberam a droga na concentração final de $1.4 \mathrm{mg} \cdot \mathrm{ml}^{-1}$, disponível na água para beber, enquanto aqueles tratados com ácido lipóico receberam uma injeção intrape- ritonial diariamente, na concentração $0,1 \mathrm{mg} \cdot \mathrm{ml}^{-1}$. Ambos foram alimentados ad libitum durante 15 dias. Após esse período, os ratos foram anestesiados com pentobarbital sódico ( $40 \mathrm{mg} / \mathrm{kg}$, i.p) e o sangue foi coletado da veia renal, prontamente centrifugado, e o plasma, isolado. Os músculos sóleo e gastrocnêmio foram isolados e retirados para avaliação bioquímica do conteúdo de glicogênio.

\subsection{Determinação da glicemia e lactatemia}

Para a determinação da concentração plasmática de glicose e lactato foram utilizados métodos enzimáticos conforme "kit" de aplicação laboratorial da Sigma Diagnósticos.

\subsection{Glicogênio muscular}

As amostras do músculo foram digeridas em $\mathrm{KOH} 30 \%$ a quente e o glicogênio foi precipitado após passagem por etanol a quente. Entre uma fase e outra da precipitação, a amostra foi centrifugada a $3000 \mathrm{rpm}$, durante 15 minutos. O glicogênio precipitado, foi submetido a hidrólise ácida na presença de fenol ${ }^{(23)}$. A leitura foi realizada a $490 \mathrm{~nm}$ e os valores foram expressos em $\mathrm{mg} / 100 \mathrm{mg}$ de peso úmido.

\subsection{Indução do diabetes}

Antes da indução da diabetes mellitus, os ratos foram mantidos em jejum por 24 horas, com livre acesso a água. Após anestesia com éter, os ratos receberam uma injeção de aloxana em salina $(40 \mathrm{mg} / \mathrm{Kg}$ de peso), através da veia peniana e, depois, foram mantidos em gaiolas individuais. O estabelecimento do diabetes foi verificado através da presença de glicose na urina.

\begin{tabular}{|ll|}
\hline \multicolumn{2}{|l|}{ Tabela I - A tabela mostra os grupos experimentais } \\
bem como o número de animais utilizados. \\
\hline GRUPOS & № \\
\hline Normal & 8 \\
Normal, tratado com metformina $1.4 \mathrm{mg} \cdot \mathrm{ml}^{-1}$ & 8 \\
Normal, tratado com ácido lipóico $0,1 \mathrm{mg} \cdot \mathrm{ml}^{-1}$ & 8 \\
Denervado & 8 \\
Denervado, tratado com metformina $1.4 \mathrm{mg} \cdot \mathrm{ml}^{-1}$ & 8 \\
Denervado, tratado com ácido lipóico $0,1 \mathrm{mg} \cdot \mathrm{ml}^{-1}$ & 8 \\
Diabético por aloxana & 8 \\
Diabético, tratado com metformina $1.4 \mathrm{mg} \cdot \mathrm{ml}^{-1}$ & 8 \\
Diabético, tratado com ácido lipóico $0,1 \mathrm{mg} \cdot \mathrm{ml}^{-1}$ & 8 \\
\hline
\end{tabular}




\subsection{Análise estatística}

A avaliação estatística dos dados foi feita através de Análise de Variância seguida do teste de Tukey. Em todos os cálculos, foi fixado o nível crítico em $\mathrm{P}<0,05(5 \%)$.

\section{RESULTADOS}

A descoberta de relações funcionais entre o sistema sinalizador da insulina e a homeostasia da junção neuromuscular vem instigando diferentes grupos de pesquisadores no sentido de buscar metodologias alternativas que possam auxiliar a minimizar o quadro de resistência à insulina, seguido de atrofia, desencadeado após a lesão na interface mioneural.

Há muito tempo, nosso grupo de pesquisa vem se dedicando a avaliar parâmetros farmacológicos e fisioterápicos que possam melhorar as condições energéticas de músculos denervados. Neste trabalho, avaliamos a ação da biguanida metformina e do ácido lipóico sobre a capacidade de sintetizar glicogênio em músculos denervados.

A Figura 1 mostra o efeito da metformina e do ácido lipóico sobre os músculos sóleo e gastrocnêmio normais. Podemos observar que, tanto no sóleo normal quanto no gastrocnêmio, houve uma elevação significativa no conteúdo de glicogênio na presença da metformina, atingindo $297 \%$ e $393 \%$ ( $\mathrm{P}<0,05)$, respectivamente. Apesar de haver uma tendência à elevação do conteúdo de glicogênio na presença do ácido lipóico, os resultados não são significativamente diferentes dos do controle.

A Figura 2 mostra o efeito da denervação sobre o conteúdo muscular de glicogênio e o efeito do tratamento com metformina e ácido lipóico. Pode-se ob- servar que o sóleo denervado apresentou uma redução de $60 \%$ no conteúdo de glicogênio, enquanto o gastrocnêmio apresentou redução de $40 \%(\mathrm{P}<0,05)$, sugerindo a existência de uma íntima relação entre a homeostasia da inervação motora e a capacidade de sintetizar glicogênio. A mesma figura mostra que a biguanida metformina promoveu uma expressiva elevação no conteúdo de glicogênio, atingindo $153 \%$ no sóleo e $225 \%$ no gastrocnêmio $(\mathrm{P}<0,05)$. Tais observações mostram que a biguanida exerce sua ação mesmo estando o músculo denervado. Com relação ao tratamento com ácido lipóico, não observamos alterações significativas no conteúdo de glicogênio dos músculos denervados, efeito similar ao observado nos músculos normais.

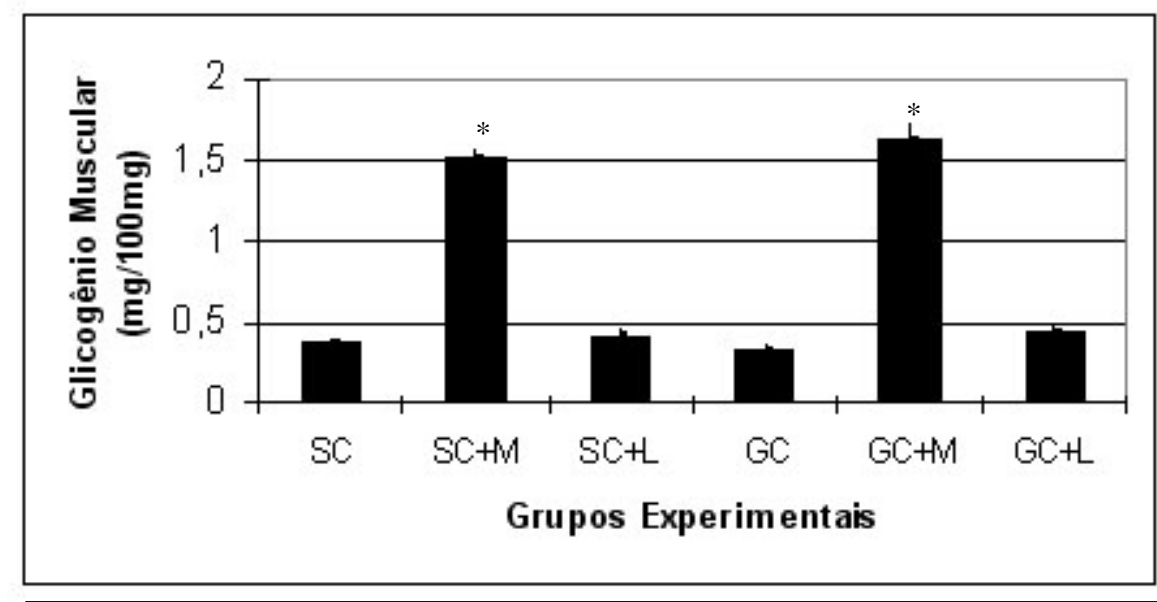

Figura 1: Concentração de glicogênio $(\mathrm{mg} / 100 \mathrm{mg})$ nos músculos sóleo (S) e gastrocnêmio $(\mathrm{G})$, controle $(\mathrm{C})$, na presença de metformina $(\mathrm{M})\left(1.4 \mathrm{mg}^{\mathrm{ml}} \mathrm{m}^{-1}\right)$ ou ácido lipóico $(\mathrm{L})\left(0.1 \mathrm{mg} \mathrm{ml}^{-1}\right)$. Os valores representam as médias \pm epm, $n=6$. ${ }^{*} P<0,05$ em relação ao normal.

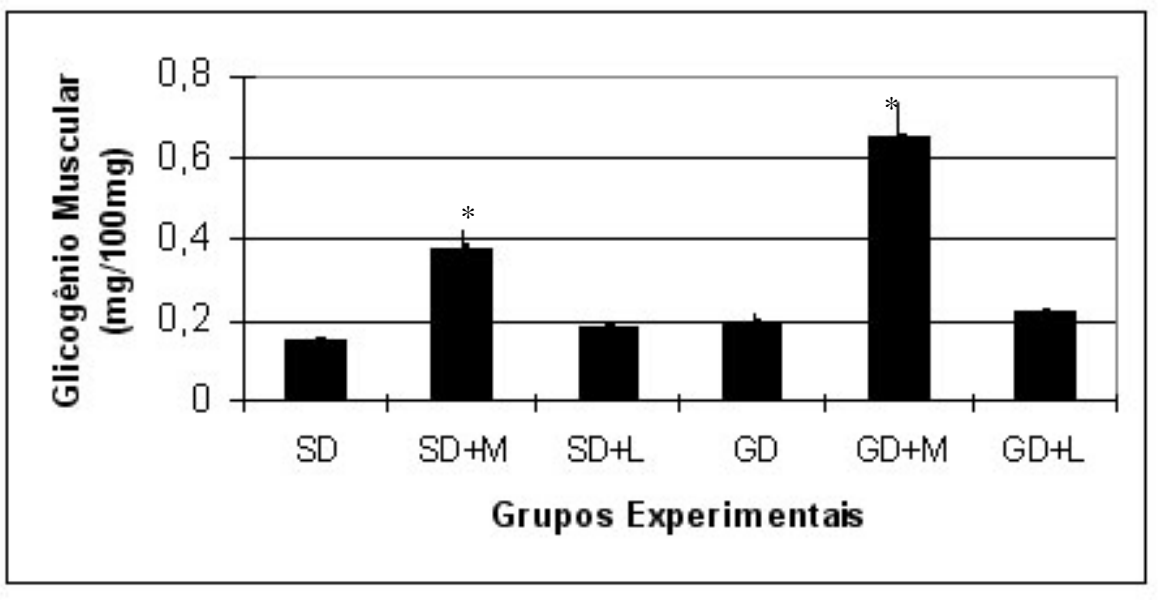

Figura 2: Concentração de glicogênio ( $\mathrm{mg} / 100 \mathrm{mg})$ nos músculos sóleo (S) e gastrocnêmio $(G)$, denervados (D), na presença de metformina (M) (1.4 mg. $\left.\mathrm{ml}^{-1}\right)$ ou ácido lipóico (L) $\left(0.1 \mathrm{mg} \mathrm{ml}^{-1}\right)$. Os valores representam as médias \pm epm, $n=6$. ${ }^{*} \mathrm{P}<0,05$ em relação ao denervado. 
Considerando-se que o diabetes mellitus promove alterações nas vias responsáveis pelo metabolismo dos carboidratos, avaliamos o efeito dos mesmos tratamentos sobre os mesmos músculos de ratos diabéticos. A Figura 3 mostra que, no diabetes, há uma diminuição na capacidade muscular de sintetizar glicogênio, representada pela redução de $50 \%$ no conteúdo de glicogênio do sóleo e $24 \%$ no gastrocnêmio $(\mathrm{P}<0,05)$. Na mesma figura, observa-se ainda que,

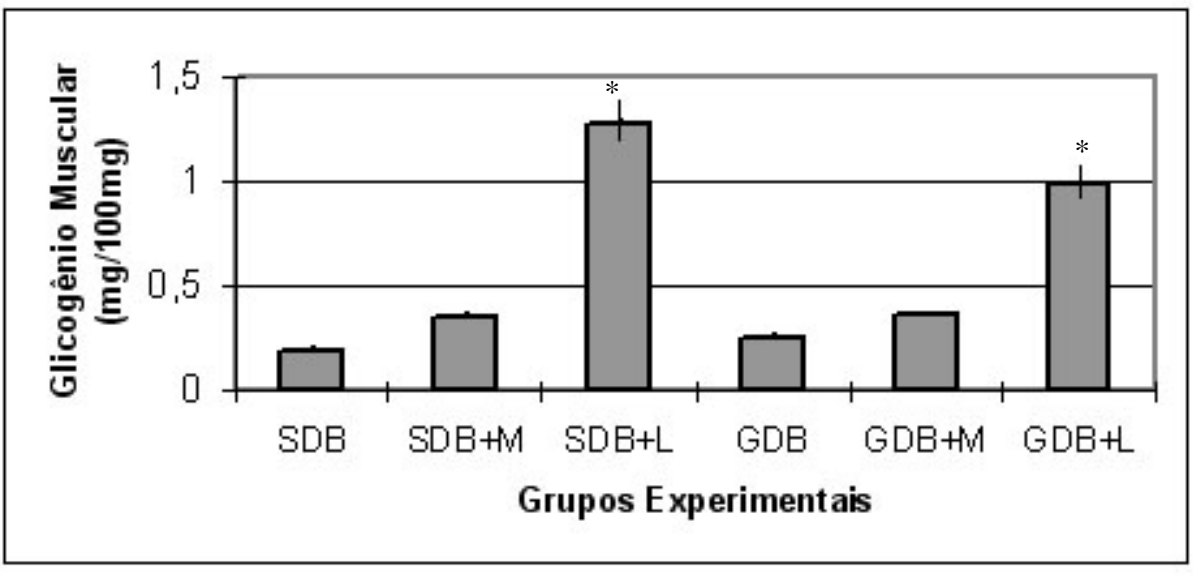

Figura 3: Concentração de glicogênio (mg/100mg) nos músculos sóleo (S) e gastrocnêmio (G) de ratos diabéticos (DB) na presença de metformina (M) $\left(1.4 \mathrm{mg}^{\left.-\mathrm{ml}^{-1}\right)}\right.$ ou ácido lipóico $(\mathrm{L})$ $\left(0.1 \mathrm{mg} \mathrm{ml}^{-1}\right)$. Os valores representam as médias $\pm \mathrm{epm}, \mathrm{n}=6$. ${ }^{*} \mathrm{P}<0,05$ em relação ao controle. na presença da metformina, $o$ conteúdo de glicogênio do sóleo foi elevado em $84 \%$ $(\mathrm{P}<0,05)$, enquanto, no gastrocnêmio, a elevação foi de 44\% ( $\mathrm{P}<0,05)$. Por outro lado, na presença do ácido lipóico, a elevação do conteúdo de glicogênio foi bem mais significativa, atingindo 573\% $(\mathrm{P}<0,05)$ no sóleo e $296 \%(\mathrm{P}<0,05)$ no gastrocnêmio, apontando a eficiência do tratamento com ácido lipóico no restabelecimento da capacidade de sintetizar glicogênio.

Tendo em vista uma possível toxicidade do tratamento, passamos a avaliar parâmetros indicadores (Tabela II). Em relação à glicemia, houve elevação de $74 \%(\mathrm{P}<0,05)$ em decorrência do diabetes, no entanto, a hiperglicemia foi reduzida em $35 \%(\mathrm{P}<0,05)$ na presença de metformina e $38 \%(\mathrm{P}<0,05)$ na presença do ácido lipóico, não sendo observada hipoglicemia nos animais normais sob tratamento. A tabela mostra, ainda, que a concentração plasmática de triglicerídeos foi elevada em $633 \%(\mathrm{P}<0,05)$ devido ao diabetes, valor que foi reduzido em $72 \%$ após tratamento com metformina e $70 \%(\mathrm{P}<0,05)$ após tratamento com ácido lipóico. Cabe salientar que os tratamentos não induziram hiperlactatemia, visto que os valores não diferem entre os grupos.

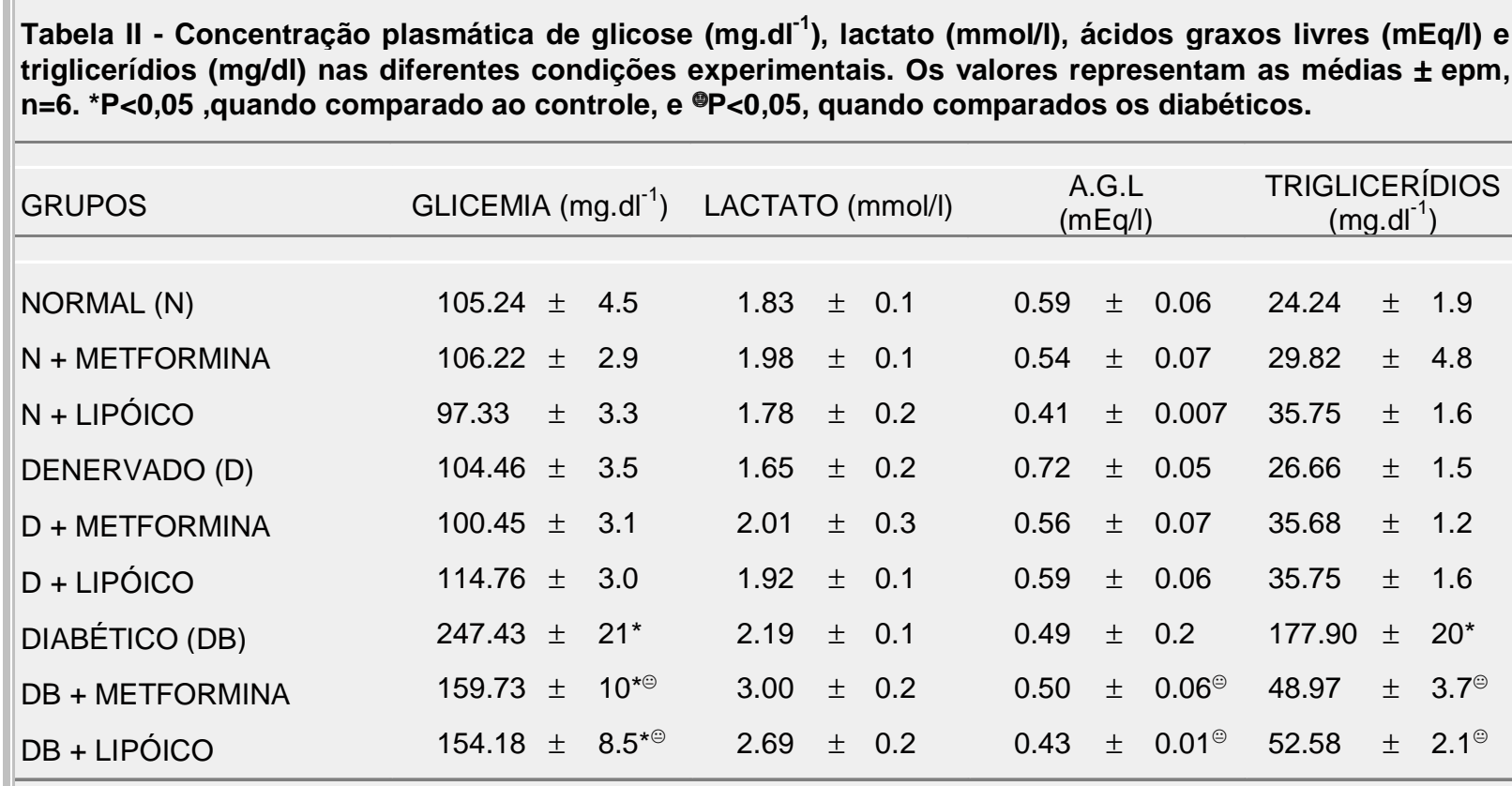




\section{DISCUSSÃO}

No tecido muscular, a insulina promove a translocação de transportadores de glicose do tipo 4 (GLUT4) para a membrana, elevando a captação de glicose e a formação de depósitos de glicogênio ${ }^{(24)}$.

Estudos, em modelos animais diabéticos, não dependentes de insulina, têm demonstrado que concomitante ao desenvolvimento da hiperglicemia, as fibras musculares esqueléticas apresentam redução no número de GLUT4, diminuição na atividade da enzima de sintetase de glicogênio e desenvolvimento do quadro de resistência à insulina. No que tange à resistência à insulina, tem-se verificado alterações no transporte de glicose pelas membranas, na síntese de glicogênio e na glicólise. Recentes estudos de ressonância magnética nuclear, confirmaram a redução na formação de glicogênio nos músculos de diabéticos ${ }^{(25)}$.

$\mathrm{Na}$ avaliação da concentração de glicogênio, no músculo de ratos diabéticos, observa-se diminuição de suas reservas, refletindo um comprometimento na dinâmica de ativação e translocação dos transportadores de glicose, assim como uma possível redução na atividade das enzimas envolvidas na síntese de glicogênio ${ }^{(26)}$.

Dentre os tratamento propostos para o diabetes tipo II, são merecedores de destaque as dietas e os agentes hipoglicemiantes orais, sendo que os últimos atuam potencializando a secreção de insulina. A utilização da biguanida metformina também visa restabelecer o quadro glicêmico em diabéticos, mas com vantagens sobre os hipoglicemiantes, pois, o restabelecimento da glicemia decorre da melhora na utilização de glicose por tecidos periféricos e bloqueio da neoglicogênese, não induzindo hipoglicemia, visto que seu efeito torna-se proporcionalmente maior com a elevação da glicemia ${ }^{(16)}$.

Para avaliar a ação da metformina sobre as concentrações de glicogênio dos músculos sóleo e gastrocnêmio de diabéticos, tratamos um grupo de ratos diabéticos por aloxana com metformina (concentração final $1.4 \mathrm{mg} \cdot \mathrm{ml}^{-1}$ ) e verificamos que a capacidade de sintetizar e reservar glicogênio foi recuperada (Figura 3). Esta recuperação se fundamentaria na ação da metformina nas vias pós-receptoras da insulina, potencializando as vias responsáveis pela captação de glicose e restabelecendo as vias de síntese de glicogênio ${ }^{(17,27)}$.

Para dirimir a dúvida, se a elevação na concentração de glicogênio, no músculo sóleo e gastrocnêmio, induzida pela metformina, ocorre somente quando existe o comprometimento enzimático observado no diabetes, um grupo de ratos normais foi submetido a tratamento com metformina. Neste grupo, verificamos que a concentração de glicogênio, no músculo sóleo e gastrocnêmio (Figura 1), apresentou significativa elevação, mostrando que o efeito da metformina se manifesta também em músculos normais ${ }^{(15)}$.

Dentro do mesmo perfil de análise, avaliamos o efeito da metformina sobre a concentração de glicogênio nos músculos sóleo e gastrocnêmio denervados. Observamos que o conteúdo de glicogênio dos músculos foi drasticamente reduzido em virtude da denervação, corroborando com a proposta de outros autores, os quais têm postulado que a secção da inervação motora promove redução nos sistemas de captação e metabolismo da glicose, sendo de fundamental importância as alterações deflagradas no pósreceptor da insulina e o desencadeamento do quadro de resistência ${ }^{(28,29)}$. Observamos que houve uma elevação no conteúdo de glicogênio dos músculos denervados tratados com metformina, sugerindo que a biguanida estimularia a cascata de eventos ligados ao sistema pós-receptor da insulina, favorecendo a síntese de glicogênio, mesmo estando o músculo denerva$\mathrm{do}^{(18)}$. Em suma, o tratamento com metformina foi benéfico por manter a homeostasia energética nos músculos denervados, podendo interferir no desencadeamento da atrofia. Cabe salientar que o desenvolvimento de atrofia não foi totalmente abolido, possivelmente porque a metformina promove a manutenção das condições energética ideais sem interferir nos parâmetros ligados ao trofismo. Recentes trabalhos de nosso grupo demonstraram que microdoses de metformina também proporcionam melhora efetiva no metabolismo das fibras musculares. Neste sentido, nosso grupo é pioneiros no estudo da ação de substâncias prescritas no tratamento de diabéticos resistentes à insulina, em músculos denervados ${ }^{(30,31,32)}$.

Inúmeros estudos têm verificado que o tratamento de diabéticos tipo II com ácido lipóico promove uma maior sensibilidade tecidual à insulina ${ }^{(33,34)}$. Diferentes estudos in vivo e in vitro, realizados com fibras musculares esqueléticas isoladas ou com miotúbulos-L6, verificaram elevação na captação de glicose e na síntese de glicogênio, após a administração de ácido lipóico ${ }^{(35,36,37)}$. Tendo como referência os estudos que ressaltam os benefícios obtidos com o tratamento com ácido lipóico, avaliamos sua ação sobre os músculos sóleo e gastrocnêmio, obtidos de ratos diabéticos ou denervados. O ácido lipóico não modifica o conteúdo de glicogênio de músculos normais ou denervados, existindo somente uma tendên- 
cia a sua elevação. No entanto, quando administrado a ratos diabéticos, houve uma significativa elevação no conteúdo muscular de glicogênio. A elevação estaria diretamente vinculada à ação do ácido lipóico como regulador dos substratos citosólicos, sinalizadores do receptor da insulina, além de atuar como cofator das enzimas que controlam a glicólise ${ }^{(38,39)}$.

Conhecendo-se os benefícios da prescrição de ácido lipóico, no tratamento da resistência à insulina em diabéticos, e comparando com os dados obtidos nos músculos denervados, que também são resistentes à insulina, onde o ácido lipóico não interferiu nas alterações dos processos ligados à formação de reservas de glicogênio, sugerimos uma possível explicação para a ausência do efeito desencadeado pelo ácido lipóico em músculos denervados. Primeiramente, a ação do ácido lipóico pode ter sido prejudicada pelo reduzido número de receptores de insulina, classicamente observado em músculos denervados. A denervação também promove a redução no conteúdo dos substratos IRS-1 e PI3K, restringindo ainda mais a ação do ácido lipóico. No entanto, sabendo-se que o ácido lipóico exerce uma discreta ação sobre a hexoquinase, sobre a translocação do GLUT4 e sobre a sintetase de glicogênio, concentrando, portanto, seu efeito na elevação dos processos oxidativos da glicose, tal via, possivelmente ativada, desencadearia uma glicopenia celular que favoreceria a captação de pequenas quantidades de glicose, refletindo na pequena elevação nas reservas de glicogênio. A dicotomia mostrada neste estudo reflete uma situação em que há redução na quantidade dos substratos sinalizadores na denervação e, por outro lado, inibição de algumas vias facilitadoras da manutenção da homeostasia energética no diabetes.

\section{CONCLUSÃO}

Frente aos resultados obtidos concluí-se que a resistência à insulina deflagrada pela secção da inervação motora, difere do quadro de resistência à insulina, desencadeado pelo diabetes. Sendo assim, sugerimos que não são todas as substâncias prescritas no tratamento de diabéticos resistentes à insulina que trariam benefícios na manutenção da homeostasia energética de músculos denervados.

SILVA CA \& GUIRRO R. The effect of metformin and lipoic acid on glycogen reserves of denervated and diabetic rat muscles. Medicina, Ribeirão Preto, 33: 490-498, oct./dec. 2000.

ABSTRACT: Insulin elicits subsequent biological responses by binding to its cell surface receptor. The insulin receptor has a citosolic substrate that is required for insulin to elicit subsequent biological signalling. Studies of target tissue of patients with noninsulin-dependent diabetes mellitus reported a decreased response to insulin compared to normal individuals. Studies in various cell types including adipocyte, muscle and liver have shown that there is a decrease in the receptor activities in various insulin-resistance states. Many works suggested that therapeutic concentrations of the antidiabetic metformin (MET) stimulates insulin receptor substrate activity. Direct activation of the insulin receptor tyrosine kinase by MET may be important in resistance states of diabetes, since that is relative clinical efficacy of this drug in stimulating insulin receptor. Recent studies have suggested that thioctic acid (TA), an antioxidant substance used in the treatment of diabetes, also has a peripheral effect that improves glucose transport and metabolism. In the present study, the metabolic effects of TA $\left(0.1 \mathrm{mg} \cdot \mathrm{ml}^{-1}\right)$ and MET $\left(1.4 \mathrm{mg} \cdot \mathrm{ml}^{-1}\right)$ were evaluated in insulin resistance induced by diabetes and muscle denervation. We observed that both denervation and diabetes reduced muscle glycogen (GLY) content soleus $60 \%$ and gastrocnemius $40 \%$ in. So and MET respectively induced an elevation in GLY reserves soleus $297 \%$ and gastrocnemius $393 \%$. In muscle of diabetic rats we observed reduction in GLY soleus $50 \%$ and gastrocnemius 24\%, however, in these muscles MET induced an elevation of GLY soleus $84 \%$ and gastrocnemius 44\%. TA also induced a signicative increase of GLY content in diabetic muscle soleus $573 \%$ and gastrocnemius $296 \%$. TA treatment did not have effect in normal and denervated muscle glycogen content. This study shows that administration of metformin is able to restore glycogen synthesis in denervated muscle and suggests that this biguanide may have potential therapeutic value to restore the metabolism of denervated muscle. However, TA is unlikely to be of therapeutic benefit in denervated muscle. This date suggests that, insulin resistance state in diabetes differ of the insulin resistance observed in denervated muscle.

UNITERMS: Metformin. Thioctic Acid. Glycogen. Muscle Denervation. 


\section{REFERÊNCIAS BIBLIOGRÁFICAS}

1 - DELA F. On the influence of physical training on glucose homeostasis. Acta Physiol Scand 158: 1-41, 1996.

2 - EXTON JH. Mechanism of hormonal regulation of hepatic glucose metabolism. Diabetes Metab Rev 3: 163-183, 1987.

3 - BACKER JM; MYERS JR.; SHOELSON SE; CHIN D; SUN XJ; MIRALPEIX P; HU B; MARGOLIS B; SKOLNIK EY; SCHLESSINGER J \& WHITE MF. The phosphatidylinisitol-3kinase is activated by association with IRS-1 during insulin stimualtion. EMBO J 11: 3469-3479, 1992.

4 - SHOELSON SE, CHATTERRJEE S; CHAUDHURI M; WHITE MF \& YALMEM W. Motifs of IRS-1 define the substrate specificty of the insulin receptor kinase. Proc Natl Acad Sci USA 89: 2027-2031, 1992.

5 - FOLLI F; SAAD MJA; BACKER JM \& KAHN CR. Insulin stimualtion of phosphatidylinositol-3- kinase activity and association with IRS-1 in liver and muscle of the intact rats. J Biol Chem 267: 22171-22177, 1992.

6 - SAAD MJA; FOLLI F; KAHN J \& KAHN CR Modulation of insulin receptor, insulin receptor substrate-1, and phosphatidylinositol-3-kinase in liver and muscle of dexamethasone-treated rats. J Clin Invest 92: 2065-2072, 1993.

7 - TSAKIRIDIS T; MCDONWELL HE; WALKER T; PETER DOWNES C;HUNDAL HS \& VRANIC K. Multiple roles of phosphatidylinositol-3- kinase in regulation of glucose transport, amino acid transport and glucose transporters in L6 skeletal muscle cells. Endocrinology 136: 4315-4322, 1995.

8 - CHEATAM B \& KHAN CR. Insulin action and the insulin signaling network. Endocr Rev 16: 117-142, 1995.

9 - KLIP A \& PAQUET MR. Glucose transport and glucose transporters in muscle and their metabolic regulation. Diabetes Care 13: 228-243, 1990.

10 - BURANT CF. Mammalian glucose transporters: Structure and molecular regulation. Recent Prog Horm Res 47: 1-45, 1991.

11 - ZIERATH CR; NOLTE LA; WAHLSTROM E; GALUSKAD; SHEPHERD PR; KAHN BB \& WALLBERG-HENRIKSSON H. Carriermediated fructose uptake significantly contributes to carbohydrate metabolism in human skeletal muscle. Biochem $\mathbf{J}$ 311: 517-521, 1995.

12 - GOODYEAR LJ; HIRSMAN MF; SMITH RJ \& HORTON ES. Glusoce transporter number. activity and isoform content in plasma membranes of red and white skeletal muscle. Am J Physiol 261: E556-561,1991.

13 - HANDBERG A; MEGENEY LA; McCULLAGH KJA; KAYSER L; HAN X \& BONEN A. Reciprocal GLUT 1 and GLUT 4 expression and glucose transport in denervated muscle. Am J Physiol 271: E50-E57, 1996.

14 - DELPRATO S; BONADONNARC; BONORAE; GULLI G; SELINI A \& SHANK M. Characterization of cellular defects of insulin action in type 2 (non-insulin-dependent) diabetes mellitus. J Clin Invest 91: 484-494, 1993.

15 - BAILEY CJ. Biguanides and NIDDM. Diabetes Care 15: 755-772, 1992.
16 - KLIP A \& LEITER LA. Cellular mechanism of action of metformin. Diabetes Care 13: 696-704, 1990.

17 - GALUSKA D; ZIERATH J; THORNE A; SONNENFELD T \& WALLBERG- HENRIKSSON H. Metformin increases insulinstimulated glucose transport in insulin resistant human skeletal muscle. Diabete Metab 17:159-163, 1991.

18 - SIU LO; RUSSEAU JC \& TAYLOR AW. Determination of glycogen in small tissue samples. J Appl Physiol 28: 234236, 1970.

19 - BAILEY CJ \& PUAH JA. Effect of metformin on glucose metabolism in mouse soleus muscle. Diabete Metab 12: 212-218, 1986.

20 - ZIEGLER D; MAYER P; MUHLEN H. \& GRIES FA. Effekte einer therapie mit alpha-liponsaure gegenuber vitamin B1 bei der diabetischen neuropathie. Diabetes Stoffw 2: 443448, 1993.

21 - JACOB S; HENRIKSEN EJ; TRITSCHLER HJ; AUGUSTIN HJ \& DIETZE GJ. Improvement of insulin-stimulated glucose disposal in type 2 diabetes after repeated parenteral administration of thioctic acid. Exp Clin Endocrinol Diabete 104: 284-288, 1996

22 - BLACK K; XIANQIN Q; SEALE JP \& DONNELLY R. Metabolic effects of thioctic acid in rodent models of insulin resistance and diabetes. Clin Exp Pharmacol Physiol 25: 712714, 1998.

23 - CODERRE L; MONFAR MM; CHEN KS; HEYDRICK SJ; KUROWSKI TG; RUDERMAN NB \& PILCH PF. Alteration in the expression of GLUT 1 and GLUT 4 Protein and messenger RNA levels in denervated rat muscle. Endocrinology 131: 1851-1825, 1992.

24 - KELLEY DE; REILLY JP \& VENEMAN T. Effects of insulin on skeletal muscle glucose storage, oxidation, and glycolysis in humans. Am J Physiol 258: E923-E929, 1990.

25 - SHULMAN GI; ROTHMAN DL; JUE T; STEIN P; DeFRONZO RA \& SHULMAN RG. Quantitation of muscle glycogen synthesis in normal subjects and subjects with non-insulin-dependent diabetes by $13 \mathrm{C}$ nuclear magnetic resonance spectroscopy. N Engl J Med 322: 223-228, 1990.

26 - De FRONZO RA; BARZILAI N; SIMONSON D. Mechanism of metformin action in obese and learn non-insulin-dependent diabetic subjects. J Clin Endocrinol Metab 73: 12941301, 1992.

27 - KLIP A; GUMA A; RAMLET T; BILAN PJ; LANN L \& LEITER LA. Stimulation of hexose transport by metformin in L6 muscle cells in culture. Endocrinology 130: 2535-2544, 1992.

28 - BURANT CF; LEMMON SK; TREUTELAAR MK \& BUSE MG. Insulin resistance of denervated rat muscle: a model for impaired receptor function coupling. Am J Physiol 247: E657-E 666, 1984.

29 - TURINSKY J. Dynamics of insulin resistance in denervated slow and fast muscle in vivo. Am J Physiol 252: E531-E 537, 1987.

30 - SILVA CA; POLACOW MLO; GUIRRO R; TANNO AP; SILVA HC \& RODRIGUES D. O efeito do fenobarbital sobre as reservas de glicogênio no músculo sóleo denervado. Rev Bras Fisioterapia 3: 35-40, 1998. 
31 - SILVA CA; POLACOW MLO; GUIRRO R; TANNO AP; SILVA HC; PARO D \& BORGES JP. Tratamento com metformina induz elevação no conteúdo de glicogênio no fígado, nos músculos e nas ilhotas de Langerhans. Rev Fac Ciênc Biol Ciênc Méd Biol (PUCC, SP) 1: 53-71, 1999.

32 - SILVA CA; POLACOW MLO; GUIRRO R; TANNO AP; SILVA $H C$ \& RODRIGUES D. Efeito da metformina e eletroestimulação sobre as reservas de glicogênio no músculo sóleo normal e denervado. Rev Bras Fisioterapia 3: 55-60, 1999.

33 - GANDHI VM; WAGH SS; NATRAJ CV \& MENON KG. Lipoic acid and diabetes II. Mode of action of lipoic acid. J Biosci 9: 117-127, 1985

34 - PACKER L; WITT EH. \& TRISCHLER HJ. Alpha-lipoic acid as a biological anti-oxidant. Free Radic Biol Med 19: 227-250, 1995.

35 - HENRIKSEN EJ \& JACOB S. Chronic thioctic acid treatment increases insulin-stimulated glucose transport activivity in skeletal muscle of obese zucker rats. Diabetes 43:122 A, 1994.Suppl. 1.
36 - HENRIKSENEJ; JACOB S; STREEPER RJ; FOGT DL; HOKAMA JY \& TRITSCHLER HJ. Stimulation by alfa-lipoic acid of glucose transport activivity in skeletal muscle of learn and obese zucker rats. Life Sci 61: 805-812, 1997.

37 - KHAMAISI M; POTASHNIK R; TIROSH A; DEMSHCHAK E; RUDICH A; TRITSCHLER H; WESSEL K \& BASHAN N. Lipoic acid reduces glycaemia and increases muscle GLUT4 content in Streptozotocin-diabetic rats. Metabolism 46:763768, 1997.

38 - HENRIKSEN EJ \& HOLLOSZY JO. Effects of phenylarsine oxide on stimulation of glucose transport in rat skeletal muscle. Am J Physiol 258: C648-653, 1990.

39 - NATRAJ CV; GANDHI VM \& MENON KKG. Lipoic acid and diabetes: Effect of dihydrolipoic acid administration in diabetic rats and rabbits. J Biosc 6:37-46, 1984

Recebido para publicação em 29/11/1999

Aprovado para publicação em 09/08/2000 